\title{
La EIB urbana en Quito. Transformaciones sociales y educativas durante la crisis global
}

\author{
The urban EIB in Quito. \\ Social and educational transformations during the global crisis \\ O BEI urbano em Quito. \\ Transformações sociais e educacionais durante a crise global \\ Freddy Simbaña Pillajo ${ }^{a}$ \\ ${ }^{a}$ Universidad Politécnica Salesiana (Ecuador). \\ Grupo de Investigación en Educación e Interculturalidad (GIEI). Ecuador. \\ fsimbana@ups.edu.ec
}

\section{RESUMEN}

El documento reflexiona sobre lo indígena y lo urbano en el contexto educativo actual y, hace una breve revisión del proceso histórico de la Unidad Educativa Comunitaria Intercultural Bilingüe (UECIB) Amawta Rikchari, en la antigua edificación de la congregación salesiana del Protectorado Católico de Artes y Oficios de Quito en 1869. Además, sitúa los avances de la Educación Intercultural Bilingüe (EIB) urbana, la institucionalización en el Distrito Metropolitano de Quito y los resultados significativos de la vigencia de la política pública educativa para los indígenas urbanos en Quito. La metodología desarrollada consta de la revisión bibliográfica para la elaboración del marco conceptual junto con el análisis documental y procesual. En materia temporal, el trabajo de campo se llevó a cabo entre octubre del 2019 hasta agosto del 2020. Más tarde, la segunda etapa fue realizada durante el confinamiento del Covid-19, mediante la recopilación y el trabajo colaborativo con docentes, estudiantes, padres y madres de familia y autoridades de la institución mediante recursos tecnológicos para la descripción cualitativa y cuantitativa. Todo ello constata los objetivos de la educación indígena en Quito, y el conocimiento de los procesos de enseñanza-aprendizaje de la Educación Intercultural Bilingüe (EIB) urbana; las expectativas y posibilidades de acceso a los estudios superiores de los estudiantes indígenas y las estrategias de dignificación del espacio barrial considerado de alta peligrosidad y criminalidad en la ciudad. Al final, se incorpora las disposiciones del Plan Educativo Covid-19 y sus transformaciones educativas para los procesos de culminación de jóvenes indígenas urbanos pertenecientes a la primera promoción de bachillerato.

Palabras claves: Indígenas urbanos, COVID-19, Educación indígena, Educación intercultural bilingüe.

\section{ABSTRACT}

The document reflects on the indigenous and the urban in the current educational context and makes a brief review of the historical process of the Amawta Rikchari Intercultural Community Educational Unit (UECIB), in the old building of the Salesian congregation of the Catholic Protectorate of Arts and Offices of Quito in 1869. In addition, it places the advances of urban Bilingual Intercultural Education (IBE), the institutionalization in the Metropolitan District of Quito and the significant results of the validity of the educational public policy for urban indigenous people in Quito. The methodology developed consists of the bibliographic review for the elaboration of the conceptual framework together with the documentary and procedural analysis. In temporal matters, the field work was carried out between October 2019 until August 2020. Later, the second stage was carried out during the confinement of Covid-19, through the collection and collaborative work with teachers, students, parents and mothers of families and authorities of the institution using technological resources for qualitative and quantitative 
description. All this confirms the objectives of indigenous education in Quito, and knowledge of the teachinglearning processes of urban Bilingual Intercultural Education (IBE); the expectations and possibilities of access to higher education for indigenous students and the strategies to dignify the neighborhood space considered highly dangerous and criminal in the city. In the end, the provisions of the Covid-19 Educational Plan and its educational transformations are incorporated for the completion processes of urban indigenous youth belonging to the first class of high school.

Key words: Urban Indigenous People, COVID-19, Indigenous Education; Bilingual intercultural education.

\section{RESUMO}

O documento reflete sobre o indígena e o urbano no atual contexto educacional e faz uma breve revisão do processo histórico da Unidade Educacional Comunitária Intercultural Amawta Rikchari (UECIB), no antigo prédio da congregação salesiana do Protetorado Católico das Artes e Escritórios de Quito em 1869. Além disso, situa os avanços da Educação Intercultural Bilíngue (IBE) urbana, a institucionalização no Distrito Metropolitano de Quito e os resultados significativos da validade da política pública educacional para os indígenas urbanos de Quito. A metodologia desenvolvida consiste na revisão bibliográfica para a elaboração do quadro conceitual em conjunto com a análise documental e procedimental. Em matéria temporal, o trabalho de campo foi realizado entre outubro de 2019 e agosto de 2020. Posteriormente, foi realizada a segunda etapa durante o confinamento da Covid-19, através da coleta e trabalho colaborativo com professores, alunos, pais e mães de familiares e autoridades da instituição utilizando recursos tecnológicos para descrição qualitativa e quantitativa. Tudo isso confirma os objetivos da educação indígena em Quito, e o conhecimento dos processos de ensino-aprendizagem da Educação Bilíngue Intercultural urbana (IBE); as expectativas e possibilidades de acesso ao ensino superior para estudantes indígenas e as estratégias para dignificar o espaço de vizinhança considerado altamente perigoso e criminoso na cidade. No final, as disposições do Plano Educacional Covid-19 e suas transformações educacionais são incorporadas aos processos de conclusão de jovens indígenas urbanos pertencentes à primeira turma do ensino médio.

Palavras chaves: Indígena urbana, COVID-19, Educação indígena, Educação intercultural bilíngue.

\section{PROCESO METODOLÓGICO}

Para la realización de esta investigación se estableció al método histórico como estrategia de trabajo, se apoya en la revisión cronológica de algunos de los hechos educativos más importantes de los pueblos y nacionalidades indígenas en la ciudad de Quito. De manera relacional, el cruce de este método con el antropológico ha permitido la elaboración de una genealogía de las dimensiones sociales, políticas, económicas, culturales y simbólicas sobre las que se han creado diferentes formas de representación respecto a la educación indígena en las ciudades.

La aplicación de esta metodología ha permitido entender el contexto en el que se generaron las representaciones contemporáneas -mediáticas sobre este sector de la población-, además aporta a identificar el origen sociocultural de diversos procesos de discriminación, así como las relaciones de poder existentes y las preconcepciones sobre la población indígena urbana.

Este trabajo se nutre de los aportes y fuentes de información que fueron recopiladas y sistematizadas tomando en cuenta el objetivo del estudio que permite indagar la educación intercultural bilingüe urbana que determine las transformaciones sociales y educativas durante la crisis global. Se utilizó bibliografía, trabajos de titulación e investigaciones producidas en centros de documentación especializados disponibles en repositorios digitales que abordan estudios referentes a los pueblos y nacionalidades indígenas. Se consultaron 
archivos históricos para la redacción de la sección sobre las misiones salesianas en Quito. Se utilizaron referencias inherentes a los instrumentos y protocolos sobre la emergencia sanitaria del Covid-19. Finalmente, se incluyeron fuentes visuales de donde se tomaron algunos textos e imágenes que muestran ciertos eventos relatados a lo largo del estudio, como es el caso de la misión salesiana a finales del siglo XIX.

De igual manera, este texto se enriqueció con las voces y testimonios provenientes de docentes, directivos, estudiantes y padres y madres de familia de pueblos y nacionalidades indígenas que se canalizaron a través de entrevistas y grupos focales vía el sistema zoom.

Finalmente, en cada etapa de la investigación se realizó la triangulación de los datos de las fuentes secundarias y primarias, al igual que de la información cualitativa y cuantitativa.

\section{SOCIEDADES INDÍGENAS URBANAS}

La presencia indígena en las ciudades en América Latina es una temática muy rica y abordada desde diversos ejes históricos, pero pocas veces visibilizada por los efectos de la colonización y las construcciones emergentes de identidades, promovidas por las repúblicas y las naciones, como producto de la modernidad.

La colonización española, a finales del siglo XV, fue el inicio no solo de una violenta imposición de un sistema económico, político y social, sino también de nuevas lógicas de pensamiento, símbolos, lenguajes y visualidades en un sinnúmero de sociedades preexistentes; condiciones que, progresivamente, permitieron la configuración de la modernidad y del sistema-mundo actual (Wallerstein y Quijano, 1992).

Hay una distinción imaginaria de los territorios indígenas asociados únicamente al mundo rural, por eso, es necesario retomar memorias que permita la reconstitución de identidades y territorios que han sido ocultados por la historia oficial de las ciudades.

Las trasformaciones identitarias de los pueblos y nacionalidades indígenas ${ }^{1}$ del Ecuador no son homogéneas, tienen distintos momentos históricos, matices y adaptaciones; inclusive se desarrollaron durante la época colonial y han podido insertarse en la sociedad mayoritaria postcolonial.

Se considera que los espacios urbanos reproducen ciertas particularidades como el fomento de la individualidad, homogenización, desindianización, aculturación, etc. aunque esto, es cuestionado por varios trabajos empíricos alrededor de toda América Latina, que demuestran la permanencia de lo indígena con, distintas prácticas, relaciones y lógicas, dentro de la urbe.

Si bien, el colonialismo, en tanto sistema de dominación político-administrativo impuesto por un Estado al ocupar territorios habitados por grupos humanos, anteriormente autónomos y ajenos a este (Quijano, 2007), fue suprimido hace más de dos siglos en el caso ecuatoriano; gran parte de sus mecanismos y lógicas de dominación, así como sus particulares relaciones de poder continúan perpetuándose en la actualidad. Esta continuidad es denominada colonialidad y se refiere "a la forma como el trabajo, el conocimiento, la autoridad y las relaciones intersubjetivas se articulan entre sí a través del mercado capitalista mundial y de la idea de raza" (Maldonado, 2007, p. 131). De tal

Art. 57.- Se reconoce y garantizará a las comunas, comunidades, pueblos y nacionalidades indígenas, de conformidad con la Constitución 2008. En adelante del texto me refiero a pueblos y nacionalidades indígenas. 
manera, "aunque el colonialismo precede a la colonialidad, la colonialidad sobrevive al colonialismo" (Maldonado, 2007, p. 131).

La situación estructural de desigualdad, racismo y violencia hacia los pueblos indígenas hace que encontremos elementos recurrentes en su inserción en la ciudad. Los colectivos indígenas se enfrentan a la realidad urbana de modo peculiar; incluso dentro de cada grupo étnico hay estrategias plurales con relación a la ocupación del espacio y a la resignificación de cuerpos y sentidos, que transitan desde la reafirmación de lo indígena hasta su negación.

De acuerdo con autores como Walter Mignolo, Aníbal Quijano, Santiago Castro Gómez o Ramón Grosfogel, la raza continúa siendo el criterio organizador fundamental del actual sistema de dominación a nivel mundial. Es justamente la continuidad de la colonialidad del poder, lo que ha establecido desde la colonia hasta hoy una escala de identidades sociales con el blanco europeo en la cima y con los indígenas y negros en los peldaños finales, "éstas últimas como identidades homogéneas y negativas" (Walsh, 2011, p. 30). Esta colonialidad, además, "se extiende a los campos del ser -la deshumanización y trato de no-existencia de algunos grupos-, y del saber -el posicionamiento del eurocentrismo y occidentalismo como modelos únicos del conocimiento, así descartando por completo a los afros e indígenas como intelectuales y como productores del conocimiento-" (Walsh, 2011, p. 30).

La nueva Constitución Política del Ecuador 2008 define al país como un Estado constitucional de derechos y justicia social. Sin embargo, la sección más importante es su reconocimiento como un Estado democrático, soberano, independiente, unitario, intercultural, plurinacional y laico, con lo que se reconoce oficialmente la existencia de varias nacionalidades indígenas dentro del territorio ecuatoriano.

La constitución de 2008 recoge algunas de las históricas aspiraciones de las poblaciones indígenas reconociendo a los grupos ancestrales como pueblos y nacionalidades. En su capítulo IV de la sección de derechos y en la participación y organización del poder se incluyen las formas ancestrales de organización social como en el caso de la Justicia Indígena, a la que se la acepta como una forma legítima de cumplir y respetar las normas y leyes que permitan una convivencia pacífica y organizada (Constitución Política del Ecuador, 2008).

Algo que no se ha modificado y sigue intacto por dos siglos, es la huella colonial en el estado y la sociedad. La situación estructural de desigualdad, racismo y violencia hacia los pueblos indígenas hace que encontremos elementos recurrentes en su inserción en la ciudad.

La participación de los pueblos y nacionalidades indígenas en los diferentes ámbitos gubernamentales como Ministerios, la Asamblea Nacional, Partidos Políticos, el reconocimiento del Shuar y el Kichwa como lenguas indígenas oficiales y el acceso a la educación, salud, vivienda y servicios públicos que fueron posibles a partir de la entrada en vigencia de las constituciones del 98 y 2008 hicieron que los indígenas se miraran como ciudadanos ecuatorianos con las mismas oportunidades, obligaciones y derechos que el resto de habitantes del país (Tuaza, 2011). Una muestra de este reconocimiento por parte de los mismos pueblos y nacionalidades indígenas se ve manifestado en ámbitos de la educación, modelos de salud y sistemas de justicia.

Tradicionalmente se hace uso de una mirada desde un "occidente genérico" para la denominación de lo indígena desde dónde se construye al otro; esta mirada justamente ayuda a constituir a un otro exótico y dificulta reconocerlo en el espacio urbano o moderno. Cada espacio urbano tiene sus particularidades, historias y topofilias. 
Discursivamente, "lo indígena" y "lo urbano" se presentan como realidades incompatibles desde una doble perspectiva que muestra a los indígenas como mera reminiscencia del pasado, produciéndose un doble alejamiento: 1) espacial, al representarlos como parte indisociable de un mundo no urbano; y 2) temporal, al reivindicar la imagen de un indígena anclado a un tiempo mítico (Albertani, 1999; Bonfil, 1990), citados en (Simbaña, 2019, p. 210).

La cercanía y la inmersión en el espacio urbano generan que el reconocimiento de los indígenas urbanos sea muy escaso en la sociedad en general e incluso desde la perspectiva de ciertos sectores del movimiento indígena ecuatoriano. Pensamiento que deriva desde la conquista y genera un sesgo historiográfico.

El eje del distanciamiento y la alteridad no son las únicas formas del abordaje de los indígenas urbanos; más bien, se pone énfasis en su articulación con los procesos educativos, sociales y económicos en los aludidos espacios urbanos. La distinción y exotización de los indígenas urbanos se debe a presupuestos construidos históricamente que distinguen entre lo tradicional y lo moderno y lo rural y lo urbano, en Engelmand (2014).

Respecto al tema del reconocimiento de identidades étnicas, es importante dejar atrás presupuestos románticos de pueblos que se han mantenido intactos, y más bien pensarlos desde una identidad en constante cambio, cargada de nuevos sentidos y nuevas formas de auto reconocimiento en la posmodernidad.

La escasa atención educativa a la población indígena ha sido una constante en la historia del Ecuador. La Educación Intercultural Bilingüe, EIB, ha asumido el desafío de enfrentar la heredad histórica de las condiciones de pobreza, desigualdad y discriminación a las cuales ha sido sometida la población indígena en las ciudades ecuatorianas.

La existencia de la EIB urbana constituye un dispositivo con diversos engranajes para que las poblaciones originarias y campesinas mantengan un continuum cultural y educativo, que permita la vivencia de una educación culturalmente pertinente en constantes revisiones, tensiones y posturas desde las mismas organizaciones indígenas frente a las políticas educativas ecuatorianas.

\section{PREVENTIVIDAD EN LA INVESTIGACIÓN URBANA}

El método preventivo de don Bosco (1815-1888), busca legitimar la inclusión del excluido, oprimido y explotado desde la capacitación educativa de jóvenes pobres producto de la sociedad industrial. Ahora el proceso urbano y el crecimiento de las ciudades tiene connotaciones diferentes de hace 50 años, la movilidad de las poblaciones encuentra insospechados desafíos, la pobreza, exclusión, estigmatización y la marginalidad avanzada y tecnológicas, están afectando a las poblaciones indígenas y constituye un sujeto emergente de investigación en las ciudades.

Los escenarios de desarrollo urbanístico y sus impactos en las ciudades ecuatorianas en las dos últimas décadas del siglo XX produce el debilitamiento y emergencia de procesos de movilización social que históricamente marcan nuevos escenarios para la disputa del poder; el debilitamiento del movimiento obrero sindical que había sido determinante en la configuración del marco legal laboral entre la década de los 60 y 70; condición que facilitaría la flexibilización de las relaciones laborales; el despertar (reconocimiento), de un movimiento indígena que luego de construir una narrativa situada, implementa prácticas de desarrollo local con un proyecto político de incidencia para sus territorios. 
Reconociéndose detrás de discursos de reivindicación étnica, propuestas para la configuración de un estado plurinacional y la autonomía en sus territorios; y, la atomización de los procesos de participación detrás de temáticas dispersas de lucha (juvenil, mujeres, artístico-cultural, generación de autoempleo...), que terminan vaciando el contenido político del movimiento social al configurar prácticas de incidencia aisladas destinadas a la inclusión de estas diversidades en marcos legales, políticas y programas de protección de igualdad a distintos grupos.

Estos elementos permiten entender un escenario sobre los modelos de desarrollo urbanístico de las grandes ciudades; Quito, Guayaquil y Cuenca quienes reproducen modelos personificados por los intereses de los sectores empresariales que inciden a través de sus representantes ligados a los gobiernos locales de cada ciudad.

En la ciudad de Quito asistimos a este escenario, el desarrollo urbano centrado en los intereses de los sectores empresariales configura un modelo basado en proyectos de grandes centros comerciales unidos a planes inmobiliarios; junto a esta situación, el proceso de inmigración interna campo-ciudad define otro elemento importante a considerar: el crecimiento desordenado de barrios marginales con presencia indígena.

La zonificación de la metrópoli fue delineada al terminar el siglo XIX y se mantuvo hasta mediados de 1920, para (Achig, 1983): el norte fue destinado para uso residencial de la clase pudiente; el centro mantuvo la misma estructura física, la clase pudiente siguió ocupando los pisos altos y la servidumbre en los pisos bajos; y el sur quedó para la clase desposeída [...] lugar con una incipiente industria, bodegas y galpones, en un completo desorden.

Existen tres dinámicas claras que configuran la ciudad de Quito: el sector Norte de la ciudad vinculado al sector financiero y al mismo tiempo con sectores periféricos; el sector Centro como la "Ciudad patrimonial" vinculado al comercio informal y poblaciones indígenas en mercados de abastos y proveedora de servicios varios; el sector Sur vinculados a centros de comercios y negocios en el que se desarrollan proyectos urbanísticos con desordenada planificación de barrios carentes de servicios básicos en zonas periféricas y barrios indígenas.

Lo anterior ha motivado el análisis y acompañamiento a las poblaciones indígenas en contextos urbanos, para ello, se necesita un soporte desde el método preventivo y una pedagogía sensible, palpable y comunicable desde la perspectiva de la interculturalidad.

La Universidad Politécnica Salesiana desde la preventividad posee un rasgo histórico con las miradas a los pueblos y nacionalidades como sujetos activos y en continua transformación desde la interculturalidad con constantes cambios, movilidad y lugares de enunciación:

[...] asumir sus métodos para entrecruzar las dimensiones de la existencia que la disciplina desconecta: ontológica (la decisión de existir en tanto autoafirmación), teleológica (las metas transgeneracionales que animan las existencias negadas), epistemológica (los métodos y las formas de pensar que han hecho posible tales existencias) y accionar (las capacidades de actuar y decidir qué hacen posible las existencias) (Juncosa, 2016, p. 64).

La opción histórica por la existencia diferenciada de los pueblos indígenas, afroecuatorianos y montubios transgeneracional promueve la discusión de los saberes 
educativos en igualdad de condiciones desde las voces de los jóvenes, y que los estudiantes se constituyan el centro de aprendizaje. Sin dejar de lado, los problemas que las sociedades indígenas conllevan niveles estructurales como el machismo o sexismo, la violencia de género, entre otros. Y, de manera integral anclar las miradas al pueblo blanco-mestizo, afroecuatoriano y montubio que poseen valores y prácticas de justicia social y luchan por sociedades justas y equitativas.

Frente a esa situación en Ecuador, la investigación salesiana ${ }^{2}$ se ha abierto a nuevas presencias en el espacio urbano para dar respuestas a las necesidades que subyacen como consecuencia de la diversidad cultural y lingüística en las ciudades. La defensa de los derechos sociales; el trabajo por la integración de las diferencias en la sociedad; nuevas presencias salesianas o en ampliación de las ya existentes que dan respuestas desde el sistema de Don Bosco. Sin olvidar que los proyectos de investigación colaborativos son un campo donde se cuidan las relaciones personales, se siembra el respeto, la tolerancia, y la solidaridad, desde el que se expande la complementariedad y la reciprocidad y se impulsa la continua construcción y ejercicios de interculturalidad.

Don Bosco no es un teórico de la pedagogía, sino un sistematizador de sus experiencias educativas en el territorio: es ante todo un excelente educador, que con su gran sabiduría y genialidad transmite con luminosidad el proceso educativo. La investigación empírica se produce mediante la observación o experiencia directa e indirecta, según don Bosco: "Mi único afán al predicar y escribir fue siempre el hacerme entender de todos, ya sea en la exposición, como en el uso de las frases más sencillas y conocidas" (IV, 649), en (Sánchez, 1996)

Para Bosco, la base de toda educación es cuestión de corazón. (BAC. 35). Con el corazón, el camino de la investigación no se nos hace difícil, así podemos llegar a obtener lo mejor de nosotros y llegar a los propósitos establecidos. La investigación no deberá convertirse en actos de palabras acumuladas sino apuntan a la transformación social.

Respecto a la reflexión sobre la interculturalidad y plurinacionalidad, según Walsh (2008), frente a los debates actuales, es importante aclarar que la interculturalidad, entendida como proyecto político, social y ético, y la plurinacionalidad son perspectivas complementarias y no opuestas. Mientras que la plurinacionalidad reconoce y describe la realidad del país en la cual distintas nacionalidades indígenas (cuyas raíces son anteriores al estado nacional), conviven con pueblos afroecuatorianos, blancos y mestizos, la interculturalidad apunta las relaciones y articulaciones por construir.

Es decir, la interculturalidad es una herramienta y un proyecto necesario en la transformación del Estado y de la sociedad, pero para que esta transformación sea realmente trascendental necesita romper con el marco uninacional (o, mejor dicho, no nacional), recalcando lo plural-nacional. Pero también, hay que tener cuidado con los términos cuando poco a poco se van institucionalizando por parte del Estado y los grupos de poder. En ese sentido, cabe recordar un pensamiento kichwa que recalcaron nuestros abuelos: Ama miski shimi yakak shunkuta, "No digas palabras dulces con corazón amargo", según (Simbaña, 2020b, p. 1994).

Este pensamiento podríamos relacionarlo con varios conceptos e ideas asociadas con el concepto de interculturalidad funcional o institucionalizada (la palabra dulce), desde el Estado y los grupos de poder, en contraste con la forma despectiva de referirse con desprecio

Grupo de investigación en Educación e Interculturalidad (GIEI) sede Quito. El autor desarrolló el proyecto Pueblos indígenas y espacio urbano intercultural en Quito, 2017-2019. 
(lo agrio/amargo), a los hechos, prácticas de la vida cotidiana de los seres comunitarios y diversos. Por tal razón, el tejido comunitario para los pueblos y nacionalidades indígenas ${ }^{3}$ ecuatorianos significa el buen vivir comunitario en el campo y la ciudad, que construye el equilibrio del ser consigo mismo, la familia, la comunidad, la calle, el espacio público, el medioambiente y las divinidades y el cosmos.

Es de suma importancia el reconocimiento de la labor de los equipos de investigación salesianos que dan respuesta a las poblaciones de cada lugar y momento, por cultivar la sensibilidad educativa y práctica de Don Bosco hacia los más débiles y desvalidos. La imaginación y creatividad por ser efectivos en nuevos contextos, el empeño por continuar en la ardua labor investigativa ante las transformaciones pedagógicas y sociales en un contexto de crisis global. El optimismo del sistema preventivo genera esperanzas hacia un futuro en el que el ser humano es el mayor bien de este mundo.

Las diferencias y los conflictos siempre han existido en el seno de la población, aunque hoy la segregación urbana, espacial y étnica tienen una especial peculiaridad presente en las ciudades. Esta realidad necesita de un marco axiológico, que el sistema preventivo tiene en la base y que facilita la convivencia intercultural, el diálogo de saberes, cohesión social, corresponsabilidad y el trabajo en redes plurales. El respeto, la acogida incondicional, la solidaridad, la equidad, la justicia, la colaboración con los demás, la responsabilidad, la coordinación y el espíritu crítico son los principales valores que se encuentran en el sistema preventivo y que favorecen el camino hacia la interculturalidad y la plurinacionalidad.

Es así, que con este marco axiológico y con principios compartidos se conectan mediante nodos históricos en la investigación con poblaciones de jóvenes indígenas pertenecientes al sistema de educación intercultural bilingüe urbana en Quito. En el siguiente apartado, presento una breve historia de la edificación donde actualmente funciona la Unidad Educativa Comunitaria Intercultural Bilingüe (UECIB) Amawta Rikchari.

\section{LA PRIMERA OBRA SALESIANA EN QUITO: LA ESCUELA DE ARTES Y OFICIOS EN QUITO}

La historia de este edificio se remonta a la época del presidente Gabriel García Moreno, que delega a la Iglesia varios aspectos vitales para el funcionamiento del Estado, entre ellos la educación. Así, con la finalidad de formar a los jóvenes en los oficios mecánicos que tenía previsto para su plan de modernización del país, en 1871 funda el llamado Protectorado Católico, una delegación de la organización norteamericana, ciudad de donde además fueron enviados los primeros profesores técnicos.

El presidente José María Plácido Caamaño, en 1888 invita al país a los primeros miembros de la Orden Salesiana desde Argentina. Los salesianos llegan al Ecuador y desembarcan en Guayaquil con un propósito: encargarse de la Escuela de Artes y Oficios (Protectorado Católico), fundada por el presidente García Moreno para la educación artesanal de niños y jóvenes de la capital, bajo el afamado «sistema preventivo» de Don Bosco, en (Almeida, 2019, p. 12).

\footnotetext{
Costa: nacionalidades Chachi y Epera; pueblo Manta-Huancavilca. Sierra: nacionalidades Awa y T’sáchila. Pueblos de la nacionalidad Kichwa en la región interandina: Caranqui, Natabuela, Otavalo, Cayampi, Kitu-kara, Panzaleo, Salasaca, Chibuleo, Quisapincha, Puruhá, Waranka, Cañari, Saraguro, Palta. Amazonía: Kichwas de la amazonía; nacionalidades Siona, Cofán, Huaorani, Shuar, Achuar, Shiwiar, Zápara.
} 
Los salesianos de inmediato comienzan con una educación técnica de calidad, inspirados por la modernidad de la revolución industrial europea. Los primeros destinatarios fueron exclusivamente niños y jóvenes huérfanos de las poblaciones indígenas alrededor de la ciudad y otros, producto de la movilidad. Todos ellos, desarrollaron habilidades técnicas, artesanales y artísticas que, con sus obras, aportaron a la construcción de la ciudad patrimonial, que actualmente existe.

El 5 de febrero de 1894 el protectorado sale de la ciudad de Quito, hacia las misiones amazónicas en Ecuador, en la provincia de Morona Santiago, en el cantón Gualaquiza donde se funda la primera comunidad salesiana en la Amazonía, según (Almeida, 2020, p. 9).

La comunidad salesiana estuvo a cargo de la institución hasta 1896, cuando fueron expulsados del país por el presidente liberal Eloy Alfaro Delgado, y desde entonces la escuela pasó a ser totalmente laica. Nombres posteriores que le dieron fue Escuela de Artes e Industria, Escuela Central Técnica del Estado y, finalmente, Colegio Central Técnico a partir de 1977.

Figura 1. Escuela de Artes y Oficios (Quito)

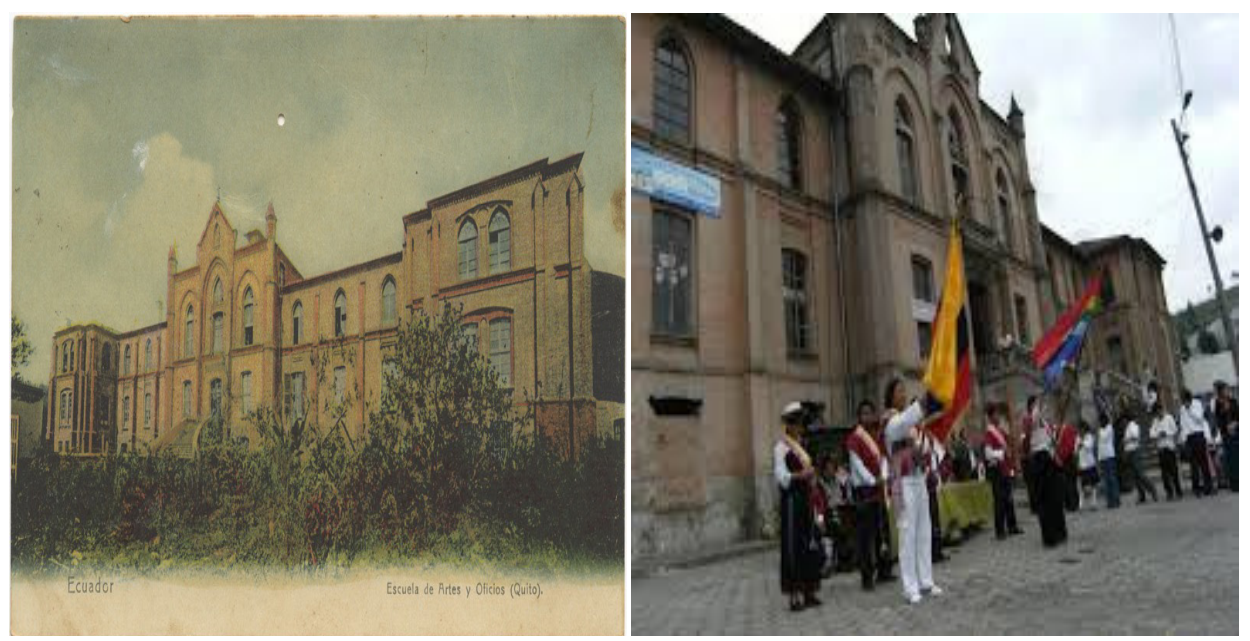

INPC: Colección Estrada Ycaza, (1935); CECIB, (2020).

Entre 1927 y 1932 la institución fue reformada y pasa la adscripción de la Universidad Central como Facultad de Ingeniería, época por la que además se amplía el edificio por el lado norte. Posteriormente, a finales de la década de 1970, el Colegio Central Técnico se traslada a su nueva sede en el norte de la ciudad, pasando el edificio de San Roque a la administración del Municipio de Quito

En el siguiente apartado, presento una breve historia sobre el estudio de caso, la UECIB Amawta Rikchari. 


\section{LA UECIB AMAWTA RIKCHARI EN LA PARROQUIA SAN ROQUE}

La Escuela Bilingüe Chimborazo data en el año 1986, orientada por la Asociación de Trabajadores Independientes Runakunapak Yuyay (ATIRY), en el centro histórico de Quito; más tarde, en 1989 la Escuela General Alejo Sáez toma el nombre en memoria al general indígena de la provincia de Riobamba, ubicada en el barrio el Panecillo y liderada por la Asociación de Indígenas kichwas residentes en Quito “Alejo Sáez”, según la UEIB (2020). Esta experiencia de escuela urbana enfoca sus esfuerzos hacia la población indígena migrante radicada en la ciudad de Quito y junto a los barrios de incidencia del trabajo de los padres y madres de familia, alrededor del mercado de San Roque y del Mercado de baratijas Ipiales.

Mediante las gestiones conjuntas entre el Movimiento indígena de Quito (MOIQ), la Asociación de Trabajadores Independiente Runacunapak Yuyay (ATIRY), y el Comité Central de Padres de Familia, el 4 de diciembre de 1993 se logra la creación del Centro Experimental de Educación Intercultural Bilingüe Quito "CEDEIB-Q", por la Dirección Provincial de Educación Intercultural de Pichincha (DIPEIB-P).

En esa edificación funcionó el Protectorado Católico en 1871 y luego la Escuela de Artes y Oficios de Quito en 1888 a cargo de misioneros salesianos. El 5 de febrero de 1894 el protectorado sale de la ciudad de Quito, hacia las misiones amazónicas (Almeida, 2020, p. 9).

Luego funciona el colegio Central Técnico desde 1871 hasta 1977. En ese entonces, las instalaciones se encontraban abandonadas y deterioradas junto al Mercado San Roque.

Con el apoyo de la fundación italiana Terre des hommes (Tdh), DIPEIB-P, el Municipio del Distrito Metropolitano de Quito y el CEDEIB-Q se firma un comodato por 25 años con la Alcaldía de Quito, el año 2005.

Entre el año 2003-2004, el Municipio del Distrito Metropolitano de Quito (MDMQ), inicia una fase de rehabilitación del Centro Histórico de Quito (CHQ), implementando una serie de programas urbanos que provocaron cambios estructurales y desplazamientos poblacionales, entre ellos los de la población indígena y empobrecida. Este traslado de personas y actividades informales fuera de los límites del centro histórico patrimonial estableció ciertas fronteras urbanas, que separan material y simbólicamente el CHQ, de los barrios aledaños identificados habitualmente por los propios quiteños como la Zona Roja, en la ciudad de Quito.

Los medios de comunicación difunden en sus noticieros la peligrosidad del barrio San Roque y han construido representaciones en los pobladores quiteños como lugares peligrosos, desorganizados e ingobernables, de muy poco acceso y de "gente mala".

La UECIB Amawta Rikchari está ubicada en una zona considerada de alta peligrosidad y con altos índices de delincuencia alrededor del mercado de abastos y legumbres.

En el año 2015 se produce el cambio de nombre de CEDEIB-Q hacia el Centro Educativo Comunitario Intercultural Bilingüe de Educación Básica Amawta Rikchari ('el despertar del sabio'), para proyectarse en un centro educativo como guardián de la lengua kichwa ${ }^{4}$. El acuerdo impulsa a la EIB urbana como integradora de saberes y propulsora del fortalecimiento de las identidades de los pueblos y nacionalidades que habitan la ciudad.

La UECIB Amawta Rikchari cuenta con 199 estudiantes de los cuales 162 pertenecen a la nacionalidad kichwa y 37 son mestizos. Existen 17 docentes en la unidad educativa de los cuales 9 pertenecen a la nacionalidad kichwa y 8 son mestizos.

Para sintetizar la reseña histórica se ha revisado el documento interno de UECIB Amawta Rikchari. 
Acerca de las relaciones laborales y trabajo de dependencia de los docentes en la unidad educativa encontramos que 4 poseen contratos ocasionales; 6 cuentan con nombramiento provisional y 7 con nombramiento definitivo.

La EIB urbana desarrolla una fuerte apropiación territorial, desde el cariño al territorio (topofilia), que demuestra e interpreta la historia y cultura rodeada de sentimientos, que conllevan a la construcción de unos lazos de la escuela indígena que resiste y se niega a desaparecer en la ciudad quiteña.

\section{LA EIB URBANA Y LA POLÍTICA EDUCATIVA}

La modalidad de escuela indígena urbana ya tiene mucho tiempo en el Ecuador y, particularmente en Quito, se acerca a los 30 años. Las políticas públicas educativas referentes a las poblaciones indígenas urbanas han merecido atención las últimas décadas.

Del año 2009, la Dirección Nacional de Educación Intercultural Bilingüe (DINEIB), perdió la autonomía técnica, financiera y administrativa; y pasó a formar parte de la Subsecretaría de Educación Intercultural Bilingüe del Ministerio de Educación A partir de este momento, el director de la entidad y los funcionarios de esta son designados por la máxima autoridad de la educación nacional.

En el año 2011, se produce la reforma de la ley de educación y se expide la Ley Orgánica de Educación Intercultural (LOEI); desaparecen las Direcciones provinciales de educación que hasta ese momento cumplían las funciones de planificación, coordinación, gestión y control de la educación de dicho ámbito jurisdiccional.

Según el artículo 25 de la LOEI, la autoridad nacional de educación se conforma por cuatro niveles de gestión; uno de representación central desde el Ministerio de Educación y tres niveles de gestión desconcentrada entre ellas: zonal intercultural y bilingüe, distrital intercultural y bilingüe, y circuitos educativos interculturales y bilingües, según el Acuerdo Ministerial No. 020, emitido el 25 de enero del 2012.

En este contexto, se institucionaliza a nivel nacional nueve Zonas Educativas, una Subsecretaría en la ciudad de Quito y otra en Guayaquil, 140 distritos educativos y 1.117 circuitos educativos. La Zona 9 abarca todo el Distrito Metropolitano de Quito (DMQ) ${ }^{5}$, y funciona la Dirección Zonal 9 de Educación Intercultural Bilingüe, con 14 instituciones.

Probablemente, la EIB urbana es percibida o relacionada con las poblaciones en procesos de migración campo y ciudad, por lo tanto "alejados de las ciudades", pero desde hace 30 años van configurándose instituciones urbanas de EIB, producto de las luchas sociales por la educación.

En el siguiente apartado, presento una breve historia de la institucionalidad y política educativa de la EIB urbana en el Distrito Metropolitano de Quito.

\section{LA EIB URBANA Y SUS INSTITUCIONES EN QUITO}

Para el 2020 en el DMQ se registra 14 instituciones educativas, 10 de ellas alcanzan el bachillerato y otras 4 llegan a cubrir la educación general básica. Para fines de agosto de

En el DMQ existen 32 parroquias urbanas y 33 rurales. 
2020 la población estudiantil alcanza a 5.776 estudiantes atendida por 254 docentes, según la Secretaría del Sistema de Educación Intercultural Bilingüe (SESEIB, 2020).

Dentro de la zona 9 correspondiente al DMQ existen 14 instituciones educativas de EIB: UECIB ${ }^{6}$ Kitu kara, UECIB Mushuk Pakari, UECIB Tinku Yachay, CECIB ${ }^{7}$ Sumak Kawsay, CECIB Muyu Kawsay, CECIB Mushuk Nina, UECIB Amawta Rikchari, CECIB Por la Paz, UECIB Mushuk Yachay, CECIB San Miguel de Conocoto, CECIB Yachay Wasi, UECIB Transito Amaguaña, UECIB Ayni Pacha y CECIB Ilaló ${ }^{8}$.

En la zona 9 existe un total de 254 docentes de los cuales son mestizos hispanohablantes el $52 \%$, equivalente a 132 docentes; el $47 \%$ son kichwa, equivalente a 120 docentes, y un $1 \%$ de afroecuatorianos, que corresponde a 2 docentes.

Con respecto a las relaciones laborales el $50 \%$ de docentes que corresponde a 128 , tiene nombramiento provisional; un $35 \%$ que equivale a 88 docentes tiene nombramiento definitivo, y un 15\%, que equivale a 38 docentes, está por contratos ocasionales.

Con respecto al número de estudiantes la zona 9 cuenta con 5.767 son estudiantes mestizos con $83,6 \%$; la nacionalidad kichwa con $13,5 \%$; la nacionalidad afroecuatoriana con $2,7 \%$; la nacionalidad chachi con $0,1 \%$ y la nacionalidad shuar con $0,1 \%$.

Dentro de la educación general básica existe un total de 4.672 estudiantes; en la educación de bachillerato son 709 estudiantes; en la Educación Infantil Familiar Comunitaria (EIFC), son 385 niños y niñas, según estos datos observamos que los la estudiantes mestizos tiene mayor porcentaje con 83,70\%; al igual que en el nivel de educación de Bachillerato con 80,25\%; y $91,43 \%$ en EIFC; seguido en menor porcentaje de la nacionalidad kichwa con $13,70 \%$ en la Educación General Básica (EGB); con 16,08\% en educación de bachillerato y con 6,75\% en EIFC.

Figura 2. Nivel de educación de la EIB zona 9

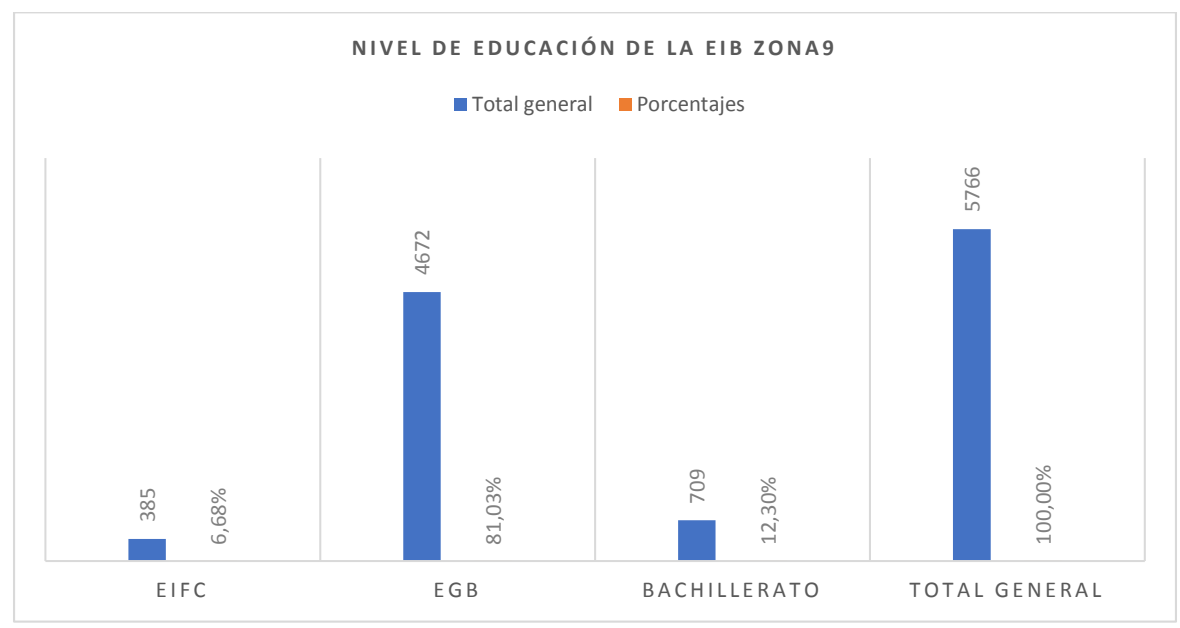

Fuente: SESIB (2020).

Unidad Educativa Intercultural Bilingüe (UECIB).

Centro Educativo Comunitario Intercultural Bilingüe (CECIB).

Escuela liderada por la comuna ancestral La Toglla perteneciente al pueblo Kitu Kara. 
De la misma manera, en porcentajes mínimos encontramos la nacionalidad afroecuatoriana con 2,76\% en EGB; con 2,96\% en la educación bachillerato y con 2,08\% en EIFC; seguido de la nacionalidad chachi con $0,02 \%$ en EGB; con $0,56 \%$ en la educación Bachillerato y $0 \%$ en EIFC, por último, la nacionalidad shuar con 0,04\% en EGB; con $0,14 \%$ en educación Bachillerato y $0 \%$ en EIFC.

Figura 3. Estudiantes de bachillerato, según nacionalidad de la EIB zona 9

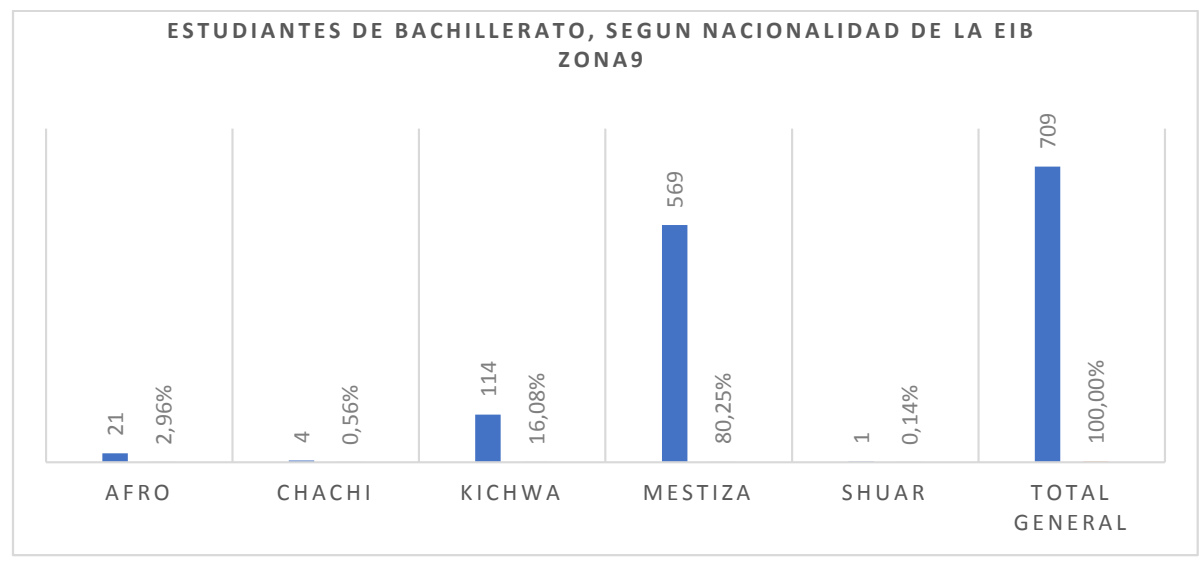

Fuente: SESIB (2020).

\section{PLAN EDUCATIVO COVID-19 EN LA UECIB AMAWTA RIKCHARI}

El Plan Educativo Covid-19 plantea una adecuación del currículo oficial vigente a la modalidad virtual, vía la compactación y priorización de sus contenidos y la oferta de un conjunto de recursos educativos y lineamientos para la selección y uso de plataformas educativas digitales.

La institución educativa Amawta Rikchari, en cumplimiento a las disposiciones emitidas por las máximas autoridades del MINEDUC, la Dirección zonal 9 y el Distrito educativo 17D04, asumió el cumplimiento obligatorio a la modalidad del Plan Educativo Covid-19.

Para la ejecución del plan de estudios del segundo quimestre año lectivo 2019-2020, se estableció que el trabajo con las Guías Integradas y dosificadas se efectuaría en los siguientes niveles:

- Educación Infantil Familiar Comunitaria, EIFC ${ }^{9}$, incluyendo el Subnivel de 3 a 4 años y el Subnivel de 4 a 5 años;

- Preparatoria, nivel destinado a la comprensión de procesos semióticos o IPS ${ }^{10}$,

Educación Infantil Familiar Comunitaria (corresponde a la educación inicial).

10 Inserción al Proceso Semiótico. 
- Nivel de Básica elemental destinado al Fortalecimiento cognitivo, afectivo y psicomotriz y denominado, FCAP ${ }^{11}$

- Nivel de la Básica Media, destinado al Desarrollo de las destrezas y técnicas de estudio, denominado DDTE ${ }^{12}$.

El Plan Educativo Covid-19 del MINEDUC se emplearía para los niveles superiores correspondientes a:

- Básica Superior, nivel destinado a Procesos de aprendizaje investigativo o PAI y,

- Bachillerato.

Los medios virtuales y tecnológicos de comunicación constituyen uno, entre varios, agentes de socialización. La escuela, la familia, el barrio, la organización, entre otros, son instituciones sociales que delimitan, refuerzan o neutralizan la influencia de los medios de comunicación en la sociedad. Por tanto, "la autonomía de la audiencia es una autonomía relativa, ya que, si bien tiene cierta libertad y creatividad, por ejemplo, para resemantizar los contenidos y formas mediáticas, lo hace siempre dentro de ciertos límites y condiciones que no son de su propia creación y que escapan a su control" (Orozco, 1997, pp. 28-29).

Las multimediaciones permiten entender el rol de los medios de comunicación como agentes activos y fuentes principales de recursos educativos, en el caso particular de esta investigación, sobre los logros y objetivos de aprendizaje. Los massmedia disponen de mecanismos sensitivos, cognitivos e ideológicos que permiten y promueven la naturalización de sentidos e ideologías específicas sobre esos grupos.

A nivel metodológico, este fenómeno mass-mediático es posible comprenderlo a través de las practicas docentes y estrategias metodológicas en los ámbitos de la teleeducación y educación virtual que la sociedad mundial está ejercitándose debido al contexto de crisis global.

\section{PROYECTO DE GRADO DE BACHILLERATO UECIB AMAWTA RIKCHARI}

El 20 de mayo de 2020 se publica oficialmente en la página del Ministerio de Educación, la disposición para que los estudiantes de $3^{\circ}$ de Bachillerato del régimen SierraAmazonía 2019-2020, realicen un Proyecto de Grado que reemplazaría al examen Ser Bachiller. Los estudiantes de Bachillerato en Ciencias desarrollarían un Estudio de Caso; los de Bachillerato Técnico, un Proyecto Demostrativo y, los alumnos del Bachillerato Internacional continuarían con el desarrollo de su monografía.

Los estudiantes acompañados de un docente tutor podían escoger entre los siguientes temas macro: información sobre el Covid-19; La convivencia; Ideas que cambiaron el mundo; La democracia; Cuidado de la naturaleza; La Interculturalidad; Los Derechos Humanos; y, La ciudadanía global. Además, los estudiantes deberán incorporar criterios de investigación sobre la identidad lingüística y cultural de su pueblo o nacionalidad (SESEIB, 2020).

11 Fortalecimiento cognitivo, afectivo y psicomotriz.

12 Desarrollo de las destrezas y técnicas de estudio. 
El proyecto de grado contemplaba un mes de trabajo en el tiempo comprendido entre el 09 al 15 de julio y la entrega final el 22 de julio de 2020; el puntaje y valoración por parte de la Comisión de Calificación conformada por docentes de la institución.

Frente al trabajo de titulación, la unidad educativa Amawta Rikchari designó a dos docentes para que trabajen con los estudiantes en el proyecto de grado, entre ellos y como encargada principal, la docente del área de investigación. En una entrevista dicha docente comenta las dificultades en el desarrollo de temáticas y ha buscado apoyo externo para la definición de temas:

[...] Para el inicio del proyecto [...], la mayor complejidad fue la creación de un tema de investigación, porque en muchos de los casos que teníamos que hablar sobre la identidad lingüística e identidad cultural. A pesar de que nuestra institución es de EIB, los chicos no estaban bien profundizados en estos temas, y por parte mía, tampoco. Fue muy complicado el desarrollo de temas, más que los medios o ámbitos del trabajo [...] (L. P., 2020).

Los temas y subtemas para los 9 estudiantes de Bachillerato fueron definidos en cinco temáticas de investigación y en el contexto de la unidad educativa, las cuales designaron un tema por dos estudiantes, y un tema designado a un solo estudiante:

\subsection{LAS VOCES DE PADRES Y MADRES DE FAMILIA SOBRE EL MODELO EDUCATIVO EIB}

En la investigación realizada por K. C. ${ }^{13}$ y M. Q. (2020), entre sus resultados coinciden en que los padres de familia consideran que el modelo educativo EIB fomenta la cultura y la identidad de cada uno de los pueblos. También, han mencionado que nunca han tenido socialización del modelo de educativo EIB, por lo tanto, desconocen su funcionalidad y más importante aún, los cambios que existen. Los padres y madres de familia sugieren procesos de capacitación y socialización para integrarse a la educación de sus hijos e hijas en la unidad educativa.

\subsection{LAS VOCES DE LOS PROFESORES INDÍGENAS SOBRE LOS RECURSOS EDUCATIVOS}

El estudiante D. P. (2020), menciona que los profesores de la institución no cuentan con recursos educativos con pertinencia cultural y lingüística, estos factores impiden el cumplimiento a cabalidad de los objetivos del MOSEIB ${ }^{14}$. Estos resultados coinciden con el trabajo del estudiante J. Q. (2020), quien también, señala la importancia de la utilización de los recursos educativos dentro del proceso de aprendizaje con pertinencia cultural.

Por estas carencias, los mismos docentes emplean recursos educativos entre los cuales los de uso más frecuente y donde se practica la convivencia son el ranti ranti y la comida comunitaria. Los profesores indican que los recursos educativos utilizados en el aula son: análisis de la vestimenta de los pueblos y nacionalidades; trabajos manuales con pertinencia cultural; bordados de camisas; y lo esencial de la oralidad y narrativa kichwa.

\footnotetext{
13 Para proteger la identidad de los estudiantes lo hemos utilizado solo los iniciales de los nombres.

14 Modelo de Educación Intercultural Bilingüe.
} 


\subsection{LAS VOCES DE LOS PROFESORES HISPANOHABLANTES SOBRE LA LENGUA KICHWA}

En la investigación de E.P. (2020) y del M. LL. (2020), coinciden en que los profesores hispanohablantes reconocen la importancia de la lengua kichwa, en la enseñanza aprendizaje para el fortalecimiento de la identidad cultural de los estudiantes. Además, los docentes dentro de EIB sugieren la ampliación del conocimiento y la práctica de la lengua kichwa para la mejora de la comunicación en el aula.

Uno de los profesores hispanohablantes entrevistados por M. LL. (2020), menciona que por ello ha buscado capacitarse en cursos de kichwa por su propia cuenta, para el cumplimento de los requisitos principales sobre la fluidez en una lengua de las nacionalidades para el acceso a una institución de EIB. Otro profesor entrevistado en el trabajo de E. P. (2020) menciona que: "no debería ser obligada a usar este idioma (kichwa), ya que si lo desean aprenderán y si no, no".

En las conclusiones generales se indica que los docentes hispanohablantes no se preocupan por adquirir los conocimientos para mejorar algunos de los aspectos determinados en el MOSEIB; resaltan la pérdida progresiva de la lengua en la educación EIB y el desinterés de los docentes en practicarla y mantenerla.

\subsection{LAS VOCES DE LAS ORGANIZACIONES INDÍGENAS SOBRE LA JURISDICCIÓN EIB}

Las organizaciones y movimientos indígenas han jugado papeles cruciales en la defensa y reclamo de los derechos en la educación, territorio, lengua y cultura; el derecho a tener una vida digna en la sociedad. Con las luchas indígenas se ha logrado la jurisdicción de EIB en la Constitución, pero en la práctica hay pendientes, según la investigación en el trabajo de A. G. (2020). Las autoridades EIB han mencionado que es lamentable que en estos momentos no exista una jurisdicción de EIB en donde se pueda actuar técnica, administrativa y financieramente. La actual Secretaría del Sistema de Educación Intercultural Bilingüe como adscrita al Ministerio de Educación tiene menos facultades, atribuciones, competencias y autonomía como anteriormente poseía la ex Dirección Nacional de Educación Intercultural Bilingüe-DINEIB. Por ello, entre las sugerencias del trabajo de A. G. (2020), enfatiza que todos los dirigentes que lideren la EIB nunca dejen la lucha educativa para algún día alcanzar una plena autonomía y que este modelo educativo se vaya extendiendo más por las zonas urbanas, en dónde las poblaciones indígenas tengan acceso a una educación sin ningún tipo de discriminación.

\subsection{LAS VOCES DE LOS ESTUDIANTES DE LA PRIMERA PROMOCIÓN DE BACHILLERES EIB SOBRE LAS ACTIVIDADES DE APRENDIZAJE}

En los resultados generales de las investigaciones realizadas de S. M. (2020), y de E. Q. (2020), se indica que las actividades de aprendizaje a lo largo del proceso de investigación les han ayudado sobre el conocimiento y la valoración de su identidad cultural. Señalan que la institución educativa no cuenta con docentes que profundicen temas y materias relacionadas a cosmovisión andina, lengua kichwa y filosofía andina. Por lo tanto, subrayan la necesidad de que los docentes desarrollen cursos o capacitaciones relacionados con las asignaturas que van a impartir, particularmente, en lo relacionado con saberes y conocimientos de pueblos y nacionalidades. 
Las investigaciones realizadas para la titulación son de carácter cualitativo y cuantitativo y presentan las opiniones e información de interlocutores cercanos.

\section{ACCESO, CONECTIVIDAD Y ACTIVIDADES ESTUDIANTILES}

A continuación, se presenta algunos datos sobre el acceso a la conectividad y las actividades que realizan los estudiantes particularmente para el proyecto de titulación; igualmente los medios usados para la comunicación docente.

Figura 4. Actividades personales estudiantiles

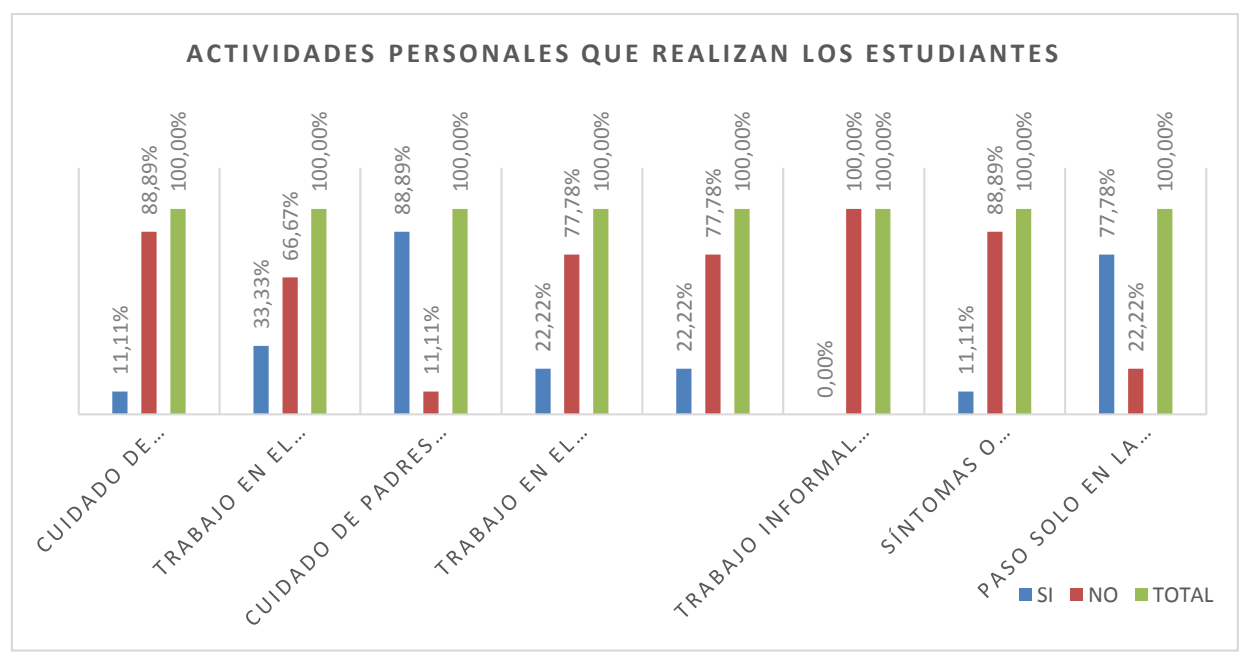

Fuente: UECIB Amawta Rikchari (2020).

Las actividades personales realizadas por los estudiantes durante el trabajo de titulación priorizan el cuidado de padres y abuelos; relevancia al trabajo en el mercado; el comercio informal y el trabajo en la construcción. 
Figura 5. Conectividad de estudiantes

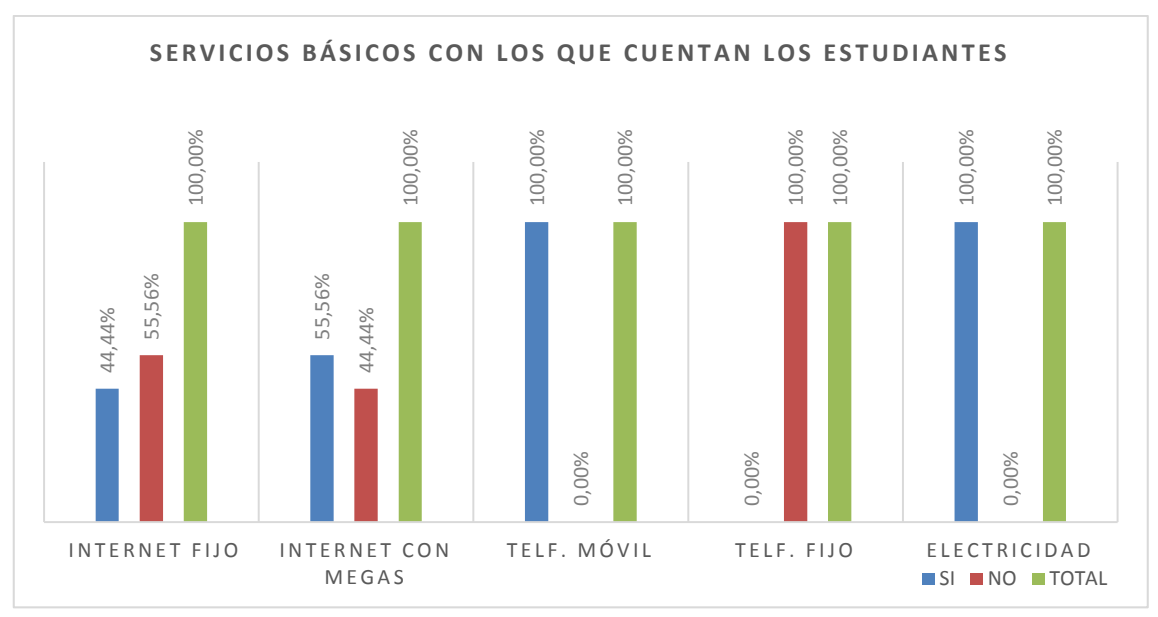

Fuente: UECIB Amawta Rikchari (2020).

El acceso de los estudiantes a la conectividad durante el trabajo de titulación; el uso de telefonía móvil; el menor acceso el internet con megas y el internet fijo. Los estudiantes carecen de telefonía fija.

Figura 6. Actividades para el proyecto de titulación

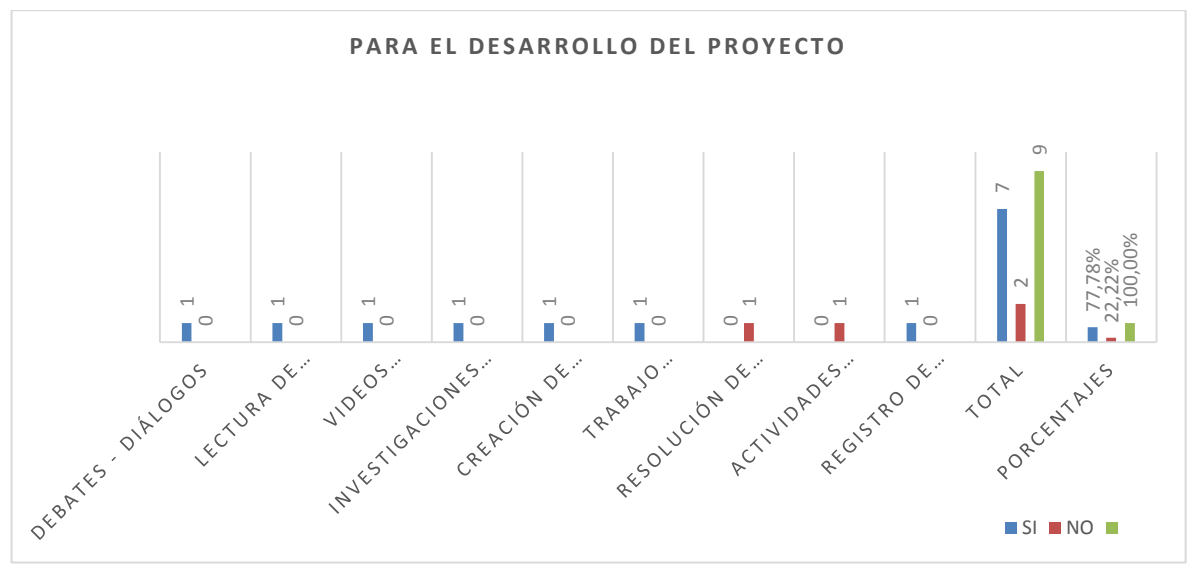

Fuente: UECIB Amawta Rikchari (2020).

Las actividades de aprendizaje más frecuentes durante el desarrollo del proyecto de titulación se refieren a debates-diálogos; lectura comprensiva de textos; videos educativos (relacionado a las experiencias de investigaciones); investigaciones en la web; creación de 
materiales de socialización y acompañamiento; trabajo colaborativo; registro de audio y video. Y, sin actividades lúdicas y resolución de problemas.

Figura 7. Medios usados para la comunicación docente-estudiante

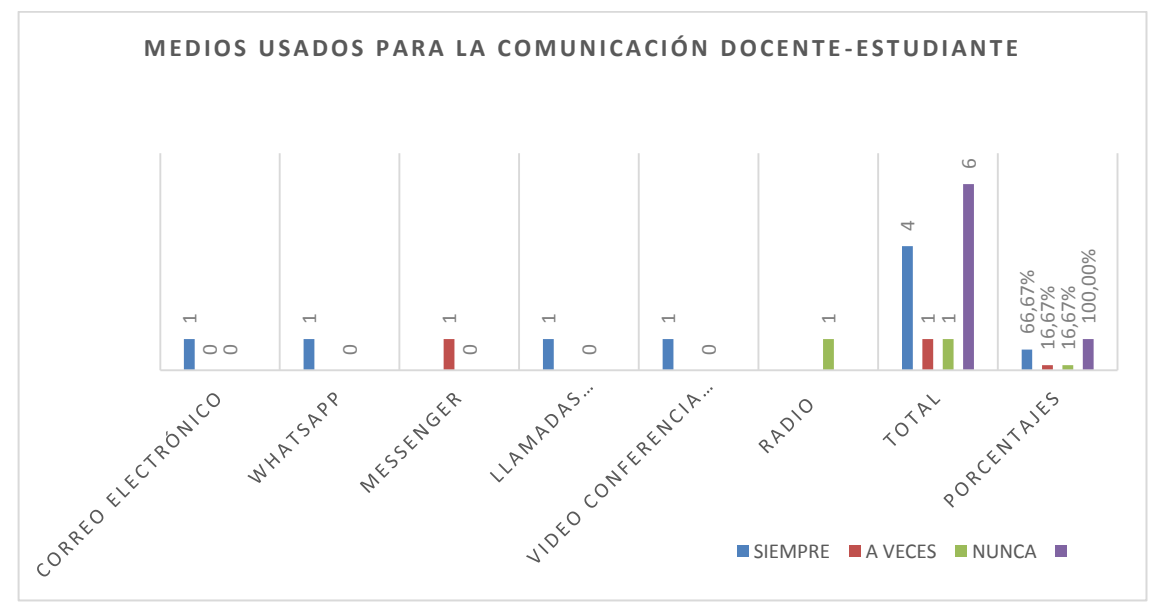

Fuente: UECIB Amawta Rikchari (2020).

Los recursos y medios más usados durante el trabajo de titulación para la comunicación docente-estudiante son el whatsapp; el correo electrónico; llamadas telefónicas; video conferencia (programa zoom); se encuentra durante el trabajo de titulación poco uso durante el trabajo de titulación de el messenger y, la radio, nunca fue utilizada.

Figura 8. Recursos educativos y proyecto de titulación

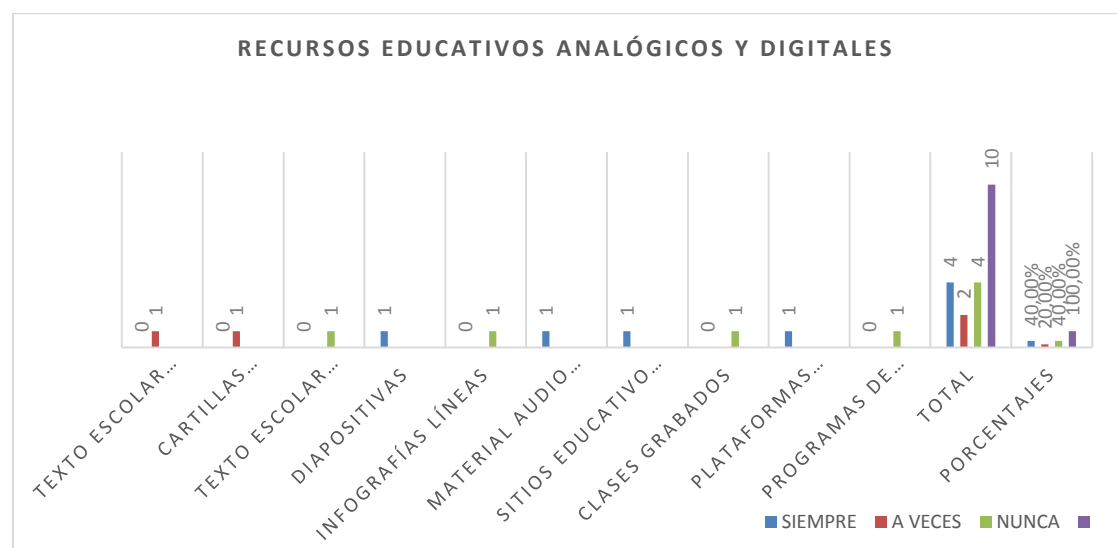

Fuente: UECIB Amawta Rikchari (2020). 
Los recursos educativos analógicos y tecnológicos más usados durante el trabajo de titulación fueron las diapositivas; audios visuales; plataformas educativas virtuales; sitios educativos abiertos; Entre los poco usados están el texto escolar y las cartillas educativas. Nunca fueron usados el texto escolar digital, las infografías y las clases grabadas.

En el desarrollo del trabajo de titulación de los estudiantes existieron algunas complicaciones, debido a la modalidad educativa virtual emergente, la ausencia de interactividad significativa y problemas de retroalimentación de comprensión, pero con el apoyo mutuo, lograron la culminación del proyecto, como nos comenta una docente:

[...] a pesar de las críticas más que ayuda recibidas de las compañeras docentes en este proceso, con la finalización (de los trabajos estudiantiles) sentí una emoción grande de que sí se pudo cumplir con las expectativas de trabajo con los chicos [...] hubiese sido mejor el trabajo con clases presenciales para interactuar de mejor manera con los estudiantes (L. P. 2020).

Por otro lado, la evaluación del trabajo de titulación se desarrolla con las directrices y disposiciones desde el Ministerio de Educación, desde una comisión gestora para la evaluación conformada por docentes de la misma institución.

\section{EXPECTATIVA DE LOS BACHILLERES EN LA UECIB AMAWTA RIKCHARI}

En la graduación virtual realizada el 29 de julio de 2020, la intervención de la mejor egresada de bachillerato D. P. (2020), expresó la importancia que tiene para los estudiantes la culminación de esta etapa formativa. La graduación fue inusual puesto que no hubo fotografías en la unidad educativa, tampoco docentes, amigos y familiares. Todo quedó grabado en el sistema zoom.

Un grupo focal -vía zoom- fue programado con los 9 estudiantes para el diálogo sobre las expectativas y planes estudiantiles a futuro. Ellos pusieron de manifiesto la dificultad para la adaptación a la educación virtual, en especial, la complejidad del trabajo que significó el proyecto de grado en esta modalidad. Manifestaron sus expectativas sobre su continuidad en la educación superior, todos coincidían sobre el problema económico puesto que sus padres y familiares viven del ingreso diario, como vendedores ambulantes, estibadores en el mercado San Roque, como albañilería y prestadores de servicios varios.

La mayoría de los estudiantes acompaña a sus padres y madres en sus trabajos y labores diarias. El esfuerzo para la finalización del bachillerato en EIB es un logro compartido. Afirman que la pandemia ha arruinado sus sueños porque sus padres no tienen trabajo y algunos familiares han decidido trasladarse a las provincias de Cotopaxi y Tungurahua en la búsqueda de lazos y vínculos familiares.

Los nuevos bachilleres no descartan la movilidad hacia el campo para integrarse a la fuerza laboral artesanal y agrícola puesto que las posibilidades de trabajo en la ciudad se presentan con dificultades. De lograr la mejora de las condiciones económicas básicas continuarán sus estudios superiores en la ciudad de Quito. 


\section{CONCLUSIONES}

Los estudios de las poblaciones indígenas producto de la movilidad histórica y contemporánea son puestos al debate, dado el interés actual, por la sistematización de experiencias pedagógicas innovadoras en el contexto de pandemia y pospandemia en las entidades educativas urbanas.

La preventividad en la investigación urbana constituye oportunidades para mirar los procesos históricos y desempeño de las misiones salesianas en las ciudades ecuatorianas con constantes cambios, movilidad e intervenciones. Así mismo, plantearse futuras investigaciones e intervenciones con pueblos indígenas urbanos desde el contexto contemporáneo.

La EIB urbana es una oportunidad para que la población indígena profundice la organización curricular, los contenidos y tratamiento metodológico propuestos por el MOSEIB; la educación y los recursos tecnológicos de comunicación, como experiencia social mediada por el lenguaje, posee una función activa y generativa que "contribuye a consolidar una determinada idea en la mentalidad de la sociedad. De ahí su importancia fundamental a la hora de configurar la percepción (y la construcción) social de la realidad, en un sentido o en otro" (Sánchez, 2010, p. 123). El uso de los recursos digitales y de la tecnología provoca procesos de enseñanza-aprendizaje creativos e innovadores para el desarrollo de habilidades, destrezas y competencias que permitan responder a los estudiantes los desafíos de la sociedad actual y para que la sociedad ecuatoriana mire en la diversidad cultural y lingüística oportunidades.

El Covid-19 ha traído rupturas en las familias indígenas urbanas y entre ellas está la desesperanza frente a la posibilidad de trabajo en las ciudades. Esto activó el retorno a las tierras de sus abuelos y padres, para reagruparse en sus comunidades para cuidarse y protegerse; a corto o mediano plazo los jóvenes bachilleres tienen previsto el retorno a la vida urbana a Quito.

La Amawta Rikchari tuvo a su cargo la primera promoción de Bachillerato, por ese motivo existía un poco de nerviosismo, primero por la responsabilidad en la asignación y definición de temas del proyecto para cada estudiante; y, luego por la necesidad de responder a los temas macro indicados desde el Ministerio de Educación, y, quizás porque lo novedoso del trabajo requería de alumnos y docentes el uso de medios virtuales y tecnológicos. Además, existía conciencia de las dificultades debidas a la carencia de acceso a computadoras e internet en los hogares de los estudiantes en situaciones de emergencia sanitaria del Covid-19.

\section{REFERENCIAS BIBLIOGRÁFICAS}

Achig, L. (1983). El proceso urbano de Quito. Quito: Centro de investigaciones CIUDAD.

Acuerdo Ministerial No. 020. (2012). Acuerdo Ministerial No. 020 - 12. Quito: Ministerio de Educación.

Albertani, C. (1999). Los pueblos indígenas en la ciudad de México. Una aproximación. Política y Cultura, 195-222.

Almeida, A. (2019). Comunidad Salesiana en Gualaquiza 125. Boletín Salesiano, 413, 9. . (2020). 124 años del colegio Don Bosco La Tola. Boletín Salesiano, 9.

Bonfil, G. (1990). México profundo. Una civilización negada. México: Grijalbo. 
Constitución de la República de Ecuador. (2008). Constitución de la República de Ecuador 2008. Montecristi: Asamblea Constituyente.

Cruz, E. (2012). Movimientos indígenas, identidad y nación en Bolivia y Ecuador. Quito: Abya-Yala.

Engelmand, J. M. (2014). Etnicidades cuestionadas: metodología y epistemología de nucleamientos y comunidades indígenas urbanas. Polis, Revista de la Universidad Bolivariana, 67-87.

Escuela de Artes y Oficios. (1927). La Escuela de Artes y Oficios de Quito. Quito: Talleres Tipográficos Nacionales.

Estatuto - Registro Oficial. (2019). Estatuto Orgánico de de Gestión Organizacional por procesos. Quito: Corte Nacional del Ecuador.

Instituto Nacional de Estadísticas y Censos. (2018). Indicadores Laborales Marzo 2018. Quito: INEC.

Juncosa, J. (2016). Buenos ciudadanos y sistema preventivo. El futuro de la preventividad. Universidad, preventividad y ciudadanía intercultural (p. 64). Quito: Abaya Yala.

LOEI. (2011). Ley Orgánica de Educación Intercultural. Quito: Ministerio de Educación.

Maldonado, N. (2007). Sobre la colonialidad del ser: contribuciones al desarrollo de un concepto. En S. C.-G. (comps.), El giro decolonial. Reflexiones para una diversidad epistémica más allá del capitalismo global. Bogotá: Siglo de Hombre Editores.

Ministerio de Educación. (31 de marzo de 2011). Mapa nacional de Coordinaciones Zonales y Direcciones Distritales. Obtenido de https://educacion.gob.ec/distritos-educativos/

Ministerio de educación. (2012). Acuerdo Ministerial No. 020 - 12. Quito: Ministerio de Educación.

Ministerio de Educación. (20 de mayo de 2020). Estudiantes de 3. ${ }^{\circ}$ de Bachillerato Proyecto de Grado. Obtenido de https://educacion.gob.ec/estudiantes-de-3-de-bachillerato-presentaranproyecto-de-grado/

Ministerio de Trabajo. (2020). Aprobación de Resolución para la suspensión de un puesto de Nivel Jerárquico Superior. Quito: MT.

Orozco, G. (1997). Medios, audiencias y mediaciones. Revista Comunicar, (8), 28-29.

Perugachi, L. (15 de agosto de 2020). Covid-19 y proyecto de Grado. (E. Fueres, Entrevistador)

Quijano, A. (2007). Colonialidad del poder y clasificación social. En R. Grosfoguel, \& S. C.G. (comps.), El giro decolonial. Reflexiones para una diversidad epistémica más allá del capitalismo global. Bogotá: Universidad Javeriana-Instituto Pensar.

Rodríguez, M. (2018). Educación intercultural bilingüe, interculturalidad y plurinacionalidad en el Ecuador. Quito: Abya Yala (Volumen 1.2).

Sánchez, D. (2010). Discriminación y medios de comunicación. Análisis de las bromas raciales en la televisión. Lima: Palestra.

Sánchez, R. (1996). 1000 Máximas Don Bosco. Buenos Aires: Centro ACS.

SESEIB. (22 de mayo de 2020). Estudiantes del tercer año de bachillerato del SEIB presentarán Proyecto de Grado con pertinencia cultural. Obtenido de https://www.educacionbilingue.gob. ec/estudiantes-del-tercer-ano-de-bachillerato-del-seib-presentaran-proyecto-de-grado-conpertinencia-cultural/

Simbaña, F. (2019). Diálogos entre pueblos indígenas y estado. Caso de pueblo Kitu Kara del Distrito Metropolitano de Quito en Ecuador. En J. Horbath \& A. Gracia, Indígenas en las ciudades de las Américas - Condiciones de vida, procesos de discriminación y lucha por la ciudadanía étnica. (pp. 209-227). Buenos Aires: Miño y Dávila editores.

. (2020a). Contribución de Ecuador. Efectos de COVID-19 en comunidades indígenas rurales y urbanas en Ecuador. En Hobarth, J \& Gracia, M. Contribución Continental al Informe del Relator Especial sobre los derechos de los pueblos indígenas sobre el Impacto de COVID-19 en los pueblos indígenas. Compilación de diecinueve contribuciones de países de las Américas. (pp. 151-160). México: Red de Investigaciones Sobre Indígenas Urbanos. RISIU.

. (2020b). Revitalización cultural después del Machakutik para el buen vivir educativo y comunitario. En Mora, A. Buenos vivires y transiciones. La vida dulce, la vida bella, la vida 
querida, la vida sabrosa, la vida buena, la vida en plenitud: convivir en armonía (pp. 175-210). Medellín: Uniminuto.

Tuaza, L. (2011). Runakunaka ashka shaikushka shinami rikurinkuna, ña mana tandanakunata munankunachu: Reflexiones sobre la crisis del Movimiento Indígena Ecuatoriano desde las bases comunitarias. Quito: FLACSO.

UECIB Sumak Kawsay. Secretaría del Sistema de Educación Intercultural Bilingüe. (2020). Guías integradoras de autoaprendizaje (dosificadas). FCAP $\left(2^{\circ} E G B\right)$. Quito.

Wallerstein, I. \& Quijano, A. (1992). "La Americanidad como concepto o América en el moderno sistema mundial”. Revista Internacional de Ciencias Sociales, 44(4), 583- 592.

Walsh, C. (2008). Interculturalidad, plurinacionalidad y decolonialidad: las insurgencias políticoepistémicas de refundar el Estado. Tabula Rasa, (9), 131-152.

Walsh, C. (2011). Interculturalidad y decolonialidad: diferencia y nación de otro modo. Quito. Obtenido de http:// http://catherine-walsh.blogspot.com.ar/2011/11/interculturalidad-ydecolonialidad.html 
